\title{
Isolation and Antimicrobial Susceptibility Profile of Shigella and Salmonella Species from Children with Acute Diarrhoea in Mekelle Hospital and Semen Health Center, Ethiopia
}

\author{
Gebremichael Gebreegziabher ${ }^{1}$, Daniel Asrat ${ }^{1}$, Yimtubezinash W/Amanuel ${ }^{1}$, \\ Tesfalem Hagos ${ }^{1}$
}

\section{OPEN ACCESS}

Citation: Gebremichael Gebreegziabher, Daniel Asrat, Yimtubezinash W/Amanuel, Tesfalem Hagos. Isolation and Antimicrobial Susceptibility Profile of Shigella and Salmonella Species from Children with Acute Diarrhoea in Mekelle Hospital and Semen Health Center, Tigray, Ethiopia. Ethiop J Sci.2018;28(2):197.

doi:http://dx.doi.org/10.4314/ejhs.v28i2.11 Received: October 28, 2017

Accepted: November 1, 2017

Published: March 1, 2018

Copyright: (C) 2018 Gebremichael Gebreegziabher, et al. This is an open access article distributed under the terms of the Creative Commons Attribution License, which permits unrestricted use, distribution, and reproduction in any medium, provided the original author and source are credited.

Funding: Addis Ababa University

Competing Interests: The authors declare that this manuscript was approved by all authors in its form and that no competing interest exists.

Affiliation and Correspondence: ${ }^{1}$ Department of Microbiology, Immunology and Parasitology, School of Medicine, College of Health Sciences, Addis Ababa University

*Email: ggteklu@gmail.com

\section{ABSTRACT}

BACKGROUND: Salmonella and Shigella remain the major contributors to acute enteric infections and diarrhoea. Hence, the objective of this study was to isolate and determine the antimicrobial susceptibility pattern of Shigella and Salmonella species from children with acute diarrhoea in Mekelle Hospital and Semen Health Center.

METHODS: A cross sectional study was conducted among 260 children with acute diarrhoea from November 2011 to March 2012 in Mekelle, Ethiopia. Stool specimen was collected from all study participants who presented with acute diarrhoea. Microscopy, culture and confirmatory identification were done by the pattern of biochemical reactions using a standard bacterial identification system (API 20E, BioMerieux, Marcy-l'Etoile, France) and polyvalent (Poly $O$ and $H$ ) antiseras for Salmonella species and $V i$ for S.typhi. Isolated colonies were assessed for antimicrobial susceptibility profile using disk diffusion method. Data was entered and analyzed using SPSS version 16.0 software.

RESULTS: Out of the 260 study participants, 145(55.8\%) were males while 115(44.2\%) were females. The majority of the patients (44.2\%) were of children under five years old. A total of 120 enteropathogens were isolated. The frequency of isolation was 19(7.3\%), 18(6.9\%) and 83(31.9\%) for Salmonella species, Shigella species and intestinal parasites respectively. Most of the Shigella isolates were resistant to ampicillin (88.9\%), Tetracycline (77.8), cotrimoxazole (55.6\%) and chloramphenicol (55.6\%). Among the Salmonella isolates, the highest resistance was observed to ampicillin (89.5\%), Tetracycline (89.5\%), chloramphenicol (78.9\%) and cotrimoxazole (57.9\%). Multi-drug resistance was noted in 19(100\%) and 16(88.9\%) of Salmonella and Shigella species respectively.

CONCLUSIONS: Shigella and Salmonella are still challenging pathogens in children $<5$ years of age. High antibiotic resistance was observed among both isolates to ampicillin, tetracycline, chloramphenicol and cotrimoxazole.

KEYWORDS: Diarrhoea, Salmonella, Shigella, Antimicrobial susceptibility, Ethiopia 


\section{INTRODUCTION}

Diarrhoea and acute gastroenteritis are among the leading causes of illness and deaths in infants and children throughout the world, especially in developing countries in situations where water supplies are contaminated and sanitation is poor (1). This is so in Asia, Africa and Latin America where an estimated 2.5 million deaths occur each year in children, resulting in over a quarter of all childhood deaths. Diarrhoea is a major cause of childhood morbidity and mortality especially in socio-economically developing countries, which remains the second leading cause of death among under-five children globally (2).

World Health Organization (WHO) has estimated that 1.5 billion episodes of diarrhoea occur every year in developing countries, resulting in 3 million deaths (3). It accounts for an estimated 12,600 deaths each day in children in Asia, Africa, and Latin America (3). Despite the wide range of treatment and prevention modalities that are available, diarrhoea still remains a major contributor to infant mortality worldwide. This is an obstacle to the achievement of Millennium Development Goal(MDG) number 4 (2). According to the Federal Democratic Republic of Ethiopia Ministry of Health (FDRE $\mathrm{MOH}$ )'s facility-based surveillance system reports, in 200203 , the proportions of diarrhoea attributable causes of under-five mortality in the country have been estimated as $20 \%$. Diarrhoeal diseases kill more children than malaria, HIV/AIDS and measles combined (4).

Diarrhoea can be caused by different agents such as bacteria, parasites and virus (5). The main etiology of the diarrhoea is related to a wide range of bacteria (such as Campylobacter jejuni, Escherichia coli, Salmonella species, Shigella species, Vibrio cholera, Yersinia enterocolitica, and Aeromonas species), enteroparasites (Giardia lamblia, Cryptosporidium species and Entamoeba histolytica), and viruses (adenovirus, Norwalk virus, and rotavirus) (5).

Among the bacterial causative agents, Salmonella and Shigella remain the major contributors to acute enteric infections and diarrhoea. The common route of infection by these pathogens is the ingestion of contaminated foods and drinks. The problem of antimicrobial resistance in bacterial pathogens causing diarrhoeal diseases continues to be alarming. Emergence and spread of antimicrobial resistance to newer and more potent agents used in treatment have been described for Salmonella and Shigella species (6).

Antimicrobial resistance has complicated the selection of antibiotics for the treatment of enteric bacterial pathogens, particularly to commonly used antimicrobial agents such as ampicillin, tetracycline and trimethoprimsulfamethoxazole (7). Since most diarrhoeal diseases are treated empirically, it is important to know the susceptibility pattern of the prevalent pathogens. In Ethiopia, there is a great need to establish the identity and antibiotic susceptibility patterns of different bacterial agents which cause enteric infections in order to introduce effective treatment for diarrhoeal illness (8).

According to Tigray Regional Health Bureau's annual report from Hospitals in 2010, diarrhoea was one of the top ten in under-five children OPD visits, admissions and deaths (9). In Mekelle, there is lack of adequate information on bacterial enteric pathogens and their antimicrobial resistance trend. Hence, this study aimed to isolate and determine the antimicrobial susceptibility profiles of Shigella and Salmonella species from children with diarrhoea in Mekelle.

\section{MATERIALS AND METHODS}

A descriptive cross-sectional study was conducted from November 2011 to March 2012 in Mekelle Hospital and Semen Health Center, Mekelle, Northern Ethiopia. These sites have higer patient load, catchment population and nearest to regional laboratory.

Inclusion and exclusion criteria: Participants who meet the following inclusion criteria were included in the study: having acute diarrhoea (the passage of loose stool by an individual, at least three times a day for $<14$ days in duration) (1), age of 6 month to 14 years and no anti-infective therapy for all of the antibiotics. We used in this 
study 48 hours prior to recruitment and informed written consent from the children's parents or guardians. Children with antibiotic treatment within 48 hours before recruitment, whose parents did not agree to participate, were less than 6 month old and those who were greater than 14 years old were excluded.

\section{Sample collection, handling and transport: Two} hundred and sixty stool specimens were collected from all study participants who presented with acute diarrhoea using dry, clean, leak proof and wide mouth stool containers after informed consent was obtained through their legal and competent guardians or parents and parasitological examination was done directly after collection by direct microscopy in the study site.

Then, after transported into the Microbiology laboratory of Mekelle Regional Health Research Laboratory using Cary Blair transport media within 2-4 hours of collection for bacteriological examination and antimicrobial susceptibility testing. The sample size was determined based on the prevalence rate of shigella spicies done by Mache on children in Jimma(16).

Processing of stool specimens: Direct microscopy of the smears in saline $(0.85 \%$ Nacl solution $)$ was performed for the detection of ova, larvae, trophozoites and cysts of intestinal parasites. Stool samples were directly inoculated using sterile cotton swabs onto MacConky agar (Oxoid; UK) and Xylose Lysine Deoxycholate (XLD) agar (Oxoid; UK), and the plates were incubated aerobically at $37^{\circ} \mathrm{C}$ for 24 hours. The same stool samples were also inoculated onto Selenite F broth enrichment media (Mast Diagnostics, UK) and incubated at $37^{\circ} \mathrm{C}$ for 24 hours, which is intended for the best recovery of Salmonella species. Following the incubation of Selenite F broth, subcultures were done onto both MAC and XLD plates and incubated at $37^{\circ} \mathrm{C}$ for 24 hours. The growth of Salmonella and Shigella species was detected by their characteristic appearance on MAC (NLF, smooth, colorless colonies, sometimes with black centered) and XLD agar (small red colonies and black-centered colonies). Confirmatory identification was done by the pattern of biochemical reactions using a standard bacterial identification system (API 20E,
BioMerieux, Marcy-l'Etoile, France) and polyvalent (Poly $\mathrm{O}$ and $\mathrm{H}$ ) antiseras for Salmonella species and Vi for S.typhi (10). We used polyvalent antisera to identify salmonella typhi from others and supported also using the API $20 \mathrm{E}$ to both salmonella and shigella species differentiation

\section{Antimicrobial susceptibility testing:}

Antimicrobial susceptibility testing was performed using the disk diffusion method. In brief, a McFarland 0.5 standardized suspension of the bacteria in $0.85 \%$ sterile saline was prepared and swabbed over the entire surface of Mueller Hinton agar (Oxoid, UK) with a sterile cotton swab (10). The inoculated plates were left at room temperature to dry for 3-5 minutes and a set of 9 antibiotic discs (Mast Diagnostics, UK) was then delivered onto the inoculated surface of MullerHinton plate with the following concentrations of the discs; ampicillin (AP) $(10 \quad \mu \mathrm{g})$, chloramphenicol (C) $(30 \mu \mathrm{g})$, gentamycin $(\mathrm{CN})(10$ $\mu \mathrm{g})$, norfloxacin (NOR) $(10 \mu \mathrm{g})$, cotrimoxazole (TS) $(25 \mu \mathrm{g})$, nalidixic acid (NA) $(30 \mu \mathrm{g})$, ceftriaxone (CRO) $(30 \mu \mathrm{g})$, ciprofloxacin (CIP) (5 $\mu \mathrm{g})$ and tetracycline $(\mathrm{T})(30 \mu \mathrm{g})$ (Mast Diagnostics, UK).

After overnight incubation at $37^{\circ} \mathrm{C}$, clear zones produced by antimicrobial inhibition of bacterial growth were measured in $\mathrm{mm}$ using a straight line ruler. The diameter of the zone was read using an interpreting chart for zone sizes. Findings of antibiotic resistance testing were recorded as susceptible, intermediate and resistant (10).

Reference strain: $E$. coli (ATCC 25922) was used as quality control throughout the study for culture and antimicrobial susceptibility testing. This strain was obtained from Ethiopian Health and Nutrition Research Institute (EHNRI).

Statistical analysis: Data was entered and analyzed using SPSS version 16.0 software. Statistical analysis was focused on the relationships between antimicrobial resistance patterns with Salmonella and Shigella species of the patients. The distribution of Shigella and Salmonella species in relation to age, sex and consistency of the stool was also analyzed. Probability values were based on two-tailed test 
results and $P$ values of $<0.05$ was considered statistically significant.

Ethical clearance: Ethical clearance was given by the Department Research and Ethical Review Committee (DREC) of Addis Ababa University. Official permission from the study sites was secured. Written informed consent was obtained from study participants' parents/ guardians. The results of the study participants with positive for enteropathogens were communicated to the attending physician for the management of the cases.

\section{RESULTS}

The number and percentage of detection of enteropathogens in diarrhoeal stool samples obtained from pediatrics patients by culture and microscopic examination is presented in Table 1. A total of 260 study participants were participated in the study. Of these, 37 participants were positive for one or more organisms. One hundred and twenty enteropathogens were isolated. Of the total 120 identified enteropathogens, 19 Salmonella species, 18 Shigella species and 83 intestinal parasites were identified.

Salmonella species: A total of 19/260 (7.3\%) Salmonella species were isolated from children with diarrhoea. Of these, 2(10.5\%) Salmonella typhi, 3(15.8\%) Salmonella paratyphi $A$ and 14(73.7\%) Salmonella species were isolated.

Table 1: Frequency of isolation of enteropathogens from the 260 children with acute diarrhoea in Mekelle Hospital and Semen Health Center, Nov. 2011 to March 2012.

\begin{tabular}{|c|c|c|c|c|}
\hline \multirow[t]{2}{*}{ Enteropathogens } & \multicolumn{2}{|c|}{ Age group in years } & \multirow[b]{2}{*}{$\begin{array}{c}>9 \\
\text { No. }(\%)\end{array}$} & \multirow[b]{2}{*}{$\begin{array}{l}\text { Total } \\
\text { No. }(\%)\end{array}$} \\
\hline & $\begin{array}{c}<5 \\
\text { No. }(\%) \\
\end{array}$ & $\begin{array}{c}5-9 \\
\text { No. }(\%) \\
\end{array}$ & & \\
\hline \multicolumn{5}{|l|}{ Salmonella } \\
\hline $\begin{array}{l}\text { Salmonella species (non typhi } \\
\text { and paratyphi A) }\end{array}$ & $11(78.6)$ & $3(21.4)$ & $0(0.0)$ & $14(100)$ \\
\hline Salmonella typhi & $0(0.0)$ & $1(50.0)$ & $1(50.0)$ & $2(100)$ \\
\hline Salmonella paratyphi A & $3(100)$ & $0(0.0)$ & $0(0.0)$ & $3(100)$ \\
\hline Total & $14(73.7)$ & $4(21.0)$ & $1(5.3)$ & $19(100)$ \\
\hline \multicolumn{5}{|l|}{ Shigella } \\
\hline Shigella species & $12(75.0)$ & $4(25.0)$ & $0(0.0)$ & $16(100)$ \\
\hline Shigella sonnei & $0(0.0)$ & $0(0.0)$ & $2(100)$ & $2(100)$ \\
\hline Total & $12(66.7)$ & $4(22.2)$ & $2(11.1)$ & $18(100)$ \\
\hline \multicolumn{5}{|l|}{ Intestinal parasites } \\
\hline Entameoba histolytica & $17(43.6)$ & $14(35.9)$ & $8(20.5)$ & $39(100)$ \\
\hline Giardia lamblia & $17(50.0)$ & $14(41.2)$ & $3(8.8)$ & $34(100)$ \\
\hline Hymenolepis nana & $0(0.0)$ & $4(80.0)$ & $1(20.0)$ & $5(100)$ \\
\hline Taenea species & $0(0.0)$ & $1(100)$ & $0(0.0)$ & $1(100)$ \\
\hline Trichuris trichuria & $0(0.0)$ & $1(100)$ & $0(0.0)$ & $1(100)$ \\
\hline Schistosoma mansonni & $1(50.0)$ & $1(50.0)$ & $0(0.0)$ & $2(100)$ \\
\hline Entrovious vermicularis & $1(100)$ & $0(0.0)$ & $0(0.0)$ & $1(100)$ \\
\hline Total & $36(43.4)$ & $35(42.2)$ & $12(14.4)$ & $83(100)$ \\
\hline
\end{tabular}

The age distributions of Salmonella were $14(73.7 \%), 4(21.1 \%)$ and $1(5.3 \%)$ in the age group of $<5,5-9,>9$ years respectively (Figure 1).
Salmonella infections were more common among children of $<5$ years of age than the other age groups $(\mathrm{p}=0.007) \quad($ Table 2$)$. The sex 
distributions of the isolates were $12(63.2 \%)$ and $7(36.8 \%)$ in males and female respectivelys. Sex has no statistically significance association with Salmonelosis $(\mathrm{p}=0.501)$. Among the 19 children who were positive for Salmonella species 9(47.4\%), 7(36.8\%), 1(5.3\%) And 2(10.5\%) were

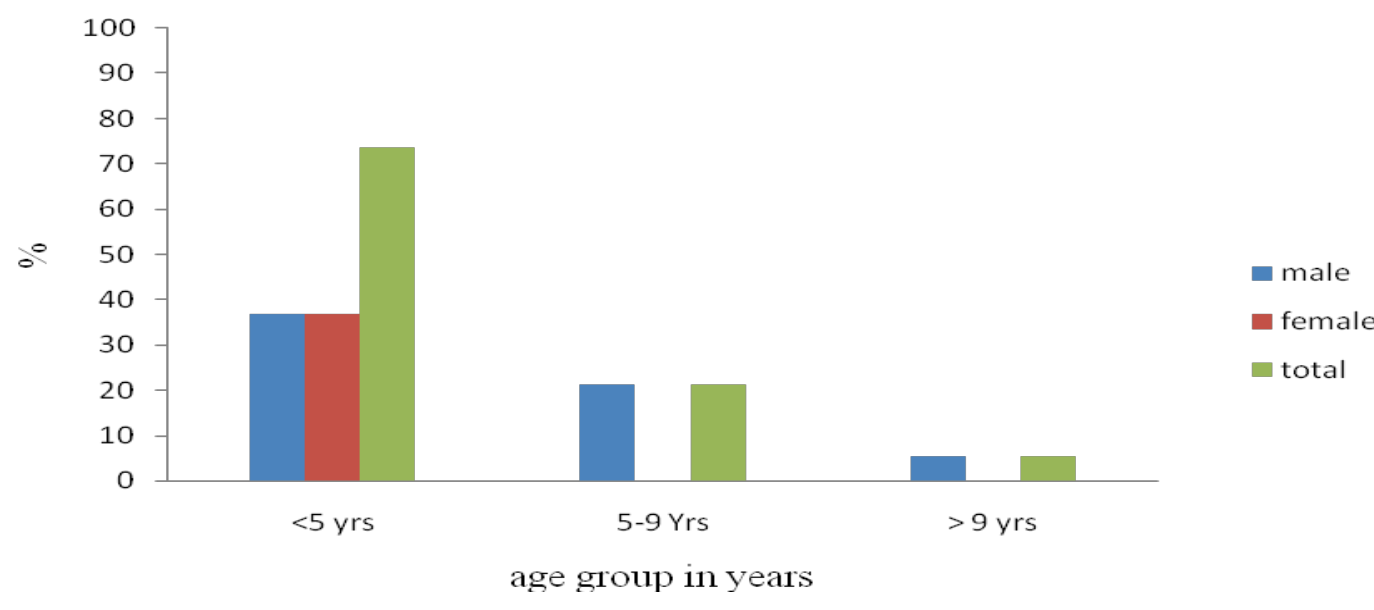

Figure 1: Age and sex distribution of children who were positive for Salmonella species in Mekelle Hospital and Semen Health Center, Nov. 2011 to March 2012.

Table 2: Association of culture positive and negative Salmonella species with age group and nature of diarrhea in Mekelle Hospital and Semen Health Center, Nov. 2011 to March 2012.

\begin{tabular}{|c|c|c|c|c|}
\hline & $\begin{array}{l}\text { Positive (\%) } \\
\text { (Salmonella } \text { spp.) } \\
\mathrm{n}=19\end{array}$ & $\begin{array}{l}\text { Negative (\%) } \\
\text { (Salmonella } \text { spp.) } \\
\mathrm{n}=241\end{array}$ & $\begin{array}{l}\text { Total }(\%) \\
n=260\end{array}$ & $\mathrm{P}$-value \\
\hline \multicolumn{5}{|c|}{ Age group in years } \\
\hline$<5$ & $\begin{array}{l}\text { Yes } 14(73.7) \\
\text { No } 5(26.3)\end{array}$ & $\begin{array}{l}101(41.9) \\
140(58.1)\end{array}$ & $\begin{array}{l}115(44.2) \\
145(55.8)\end{array}$ & 0.007 \\
\hline $5-9$ & $\begin{array}{l}\text { Yes } 4(21.1) \\
\text { No } 15(78.9)\end{array}$ & $\begin{array}{l}104(43.2) \\
137(56.8)\end{array}$ & $\begin{array}{l}108(41.5) \\
152(58.5)\end{array}$ & 0.06 \\
\hline$>9$ & $\begin{array}{l}\text { Yes } 1(5.3) \\
\text { No } 18(94.7)\end{array}$ & $\begin{array}{l}36(14.9) \\
205(85.1)\end{array}$ & $\begin{array}{l}37(14.2) \\
223(85.8)\end{array}$ & 0.245 \\
\hline $\begin{array}{l}\text { Nature } \\
\text { Watery }\end{array}$ & arrhoea & & & \\
\hline & $\begin{array}{l}\text { Yes } 9(47.4) \\
\text { No } 10(52.6)\end{array}$ & $\begin{array}{l}154(63.9) \\
87(36.1)\end{array}$ & $\begin{array}{l}163(62.7) \\
97(37.3)\end{array}$ & 0.151 \\
\hline Mucoid & $\begin{array}{l}\text { Yes } 7(36.8) \\
\text { No } 12(63.2)\end{array}$ & $\begin{array}{l}69(28.6) \\
172(71.4)\end{array}$ & $\begin{array}{l}76(29.2) \\
184(70.8)\end{array}$ & 0.449 \\
\hline Bloody & $\begin{array}{l}\text { Yes } 1(5.3) \\
\text { No } 18(94.7)\end{array}$ & $\begin{array}{l}11(4.6) \\
230(95.4)\end{array}$ & $\begin{array}{l}12(4.6) \\
248(95.4)\end{array}$ & 0.889 \\
\hline Mixed & $\begin{array}{l}\text { Yes } 2(10.5) \\
\text { No } 17(89.5)\end{array}$ & $\begin{array}{l}7(2.9) \\
234(97.1)\end{array}$ & $\begin{array}{l}9(3.5) \\
251(96.5)\end{array}$ & 0.080 \\
\hline
\end{tabular}

DOI: http://dx.doi.org/10.4314/ejhs.v28i2.11 
Shigella species: A total of 18/260 (6.9\%) Shigella species were isolated from children with diarrhoea. Of these, 2(11.1) Shigella sonnei and $16(88.9 \%)$ Shigella species were isolated. The distributions of Shigella isolates in different age groups were $12(66.7 \%), 4(22.2 \%)$ and $2(11.1 \%)$ in the age group of $<5,5-9,>9$ years respectively as shown in figure 1. Shigella infections were more common among children of $<5$ years of age than the other age groups $(\mathrm{p}=0.047)$. Among the 18 children who were positive for Shigella species, $\quad 6(33.3 \%), \quad 8(44.4 \%), \quad 3(16.7 \%)$ and $1(5.6 \%)$ were isolated from watery, mucoid, bloody and mixed diarrhoea respectively. Isolations of shigellosis were statistically associated with bloody diarrhoea $(p=0.012)$ (Table 3).

Table 3: Association of isolation of Shigella species with age group and nature of diarrhea in Mekelle Hospital and Semen Health Center, Nov. 2011 to March 2012.

\begin{tabular}{|c|c|c|c|c|}
\hline & $\begin{array}{l}\text { Positive (\%) } \\
\text { (Shigella } \text { spp.) } \\
\mathrm{n}=18\end{array}$ & $\begin{array}{l}\text { Negative (\%) } \\
\text { (Shigella } \text { spp.) } \\
\mathrm{n}=242\end{array}$ & $\begin{array}{l}\text { Total }(\%) \\
\mathrm{N}=260\end{array}$ & P-value \\
\hline \multicolumn{5}{|c|}{ Age group in years } \\
\hline$<5$ & $\begin{array}{l}\text { Yes } 12(66.7) \\
\text { No } 6(33.3)\end{array}$ & $\begin{array}{l}103(42.6) \\
139(57.4)\end{array}$ & $\begin{array}{l}115(44.2) \\
145(55.8)\end{array}$ & 0.047 \\
\hline $5-9$ & $\begin{array}{l}\text { Yes } 4(22.2) \\
\text { No } 14(77.8)\end{array}$ & $\begin{array}{l}104(43) \\
138(57)\end{array}$ & $\begin{array}{l}108(41.5) \\
152(58.5)\end{array}$ & 0.085 \\
\hline$>9$ & $\begin{array}{l}\text { Yes } 2(11.1) \\
\text { No } 16(88.9)\end{array}$ & $\begin{array}{l}35(14.5) \\
207(85.5)\end{array}$ & $\begin{array}{l}37(14.2) \\
223(85.8)\end{array}$ & 0.695 \\
\hline $\begin{array}{l}\text { Nature } \\
\text { Watery }\end{array}$ & & & & \\
\hline & $\begin{array}{l}\text { Yes } 6(33.3) \\
\text { No } 12(66.7)\end{array}$ & $\begin{array}{l}157(64.9) \\
85(35.1)\end{array}$ & $\begin{array}{l}163(62.7) \\
97(37.3)\end{array}$ & 0.08 \\
\hline Mucoid & $\begin{array}{l}\text { Yes } 8(44.4) \\
\text { No } 10(55.6)\end{array}$ & $\begin{array}{l}68(28.1) \\
174(71.9)\end{array}$ & $\begin{array}{l}76(29.2) \\
184(70.8)\end{array}$ & 0.141 \\
\hline Bloody & $\begin{array}{l}\text { Yes } 3(16.7) \\
\text { No } 15(83.3)\end{array}$ & $\begin{array}{l}9(3.7) \\
233(96.3)\end{array}$ & $\begin{array}{l}12(4.6) \\
248(95.4)\end{array}$ & 0.012 \\
\hline Mixed & $\begin{array}{l}\text { Yes } 1(5.6) \\
\text { No } 17(94.4)\end{array}$ & $\begin{array}{l}8(3.3) \\
234(96.7)\end{array}$ & $\begin{array}{l}9(3.5) \\
251(96.5)\end{array}$ & 0.614 \\
\hline
\end{tabular}

Antimicrobial susceptibility pattern

salmonella species: The antimicrobial susceptibility testing was done on all Salmonella isolates using disk diffusion method; the results are presented in Table 4. Among the 19 Salmonella isolates, the overall rates of resistance were ampicillin 17(89.5\%), tetracycline 17(89.5), chloramphenicol 15(78.9\%), cotrimoxazole 11 $(57.9 \%)$, nalidixic acid $6(31.6 \%)$, gentamicin $3(15.8 \%)$, ceftriaxone $2(10.5 \%)$ and norfloxacin $1(5.3 \%)$. All isolates were sensitive to ciprofloxacin. 
Table 4: Age and sex distribution of children positive for intestinal parasites in Mekelle Hospital and Semen Health Center, Nov. 2011 to March 2012.

\begin{tabular}{lccc}
\hline Age group in year & \multicolumn{2}{c}{ Sex no. (\%) } & Total \\
& Male & Female & $36(43.4)$ \\
$<5$ & $20(24.1)$ & $16(19.3)$ & $35(42.2)$ \\
$5-9$ & $23(27.7)$ & $12(14.5)$ & $12(14.4)$ \\
$>9$ & $9(10.8)$ & $3(3.6)$ & $\mathbf{8 3}(\mathbf{1 0 0})$ \\
\hline
\end{tabular}

Shigella species: The results of the antimicrobial susceptibility pattern of Shigella isolates are summarized in Table 5. Among the 18 Shigella isolates, the overall rates of resistance were ampicillin $16(88.9 \%)$, tetracycline $14(77.8 \%)$, chloramphenicol 10(55.6\%), cotrimoxazole $10(55.6 \%)$, nalidixic acid 5(27.8\%) and gentamicin 5(27.8\%). All isolates were 94.4-
$100 \%$ susceptible to ciprofloxacin, ceftriaxone and norfloxacin. Resistance to one or more antimicrobial agent(s) was noted in $17(94.4 \%)$ of the isolates.

Multi-drug resistance (MDR): Multi-drug resistance (resistance to two or more drugs) was observed in 19/19(100\%) and 16/18(88.9\%) of Salmonella and Shigella isolates (Table 6).

Table 5: Antimicrobial Susceptibility Profile of Salmonella species $(\mathrm{n}=19)$ isolated from children in Mekelle Hospital and Semen Health Center, Nov. 2011 to March 2012.

\begin{tabular}{llll}
\hline Antimicrobial agents & $\begin{array}{l}\text { Susceptible } \\
\text { No. (\%) }\end{array}$ & $\begin{array}{l}\text { Intermediate } \\
\text { No. }(\%)\end{array}$ & $\begin{array}{l}\text { Resistance } \\
\text { No. }(\%)\end{array}$ \\
\hline Ampicillin & $2(10.5)$ & $0(0.0)$ & $17(89.5)$ \\
Co-trimoxazole & $7(36.8)$ & $1(5.3)$ & $11(57.9)$ \\
Chloramphenicol & $3(15.8)$ & $1(5.3)$ & $15(78.9)$ \\
Norfloxacin & $17(89.5)$ & $1(5.3)$ & $1(5.3)$ \\
Tetracycline & $2(10.5)$ & $0(0.0)$ & $17(89.5)$ \\
Gentamicin & $16(84.2)$ & $0(0.0)$ & $3(15.8)$ \\
Ceftriaxone & $17(89.5)$ & $0(0.0)$ & $2(10.5)$ \\
Nalidixic acid & $12(63.1)$ & $1(5.3)$ & $6(31.6)$ \\
Ciprofloxacin & $19(100)$ & $0(0.0)$ & $0(00.0)$ \\
\hline
\end{tabular}

Table 6. Antimicrobial Susceptibility Profile of Shigella species isolated from children in Mekelle Hospital and Semen Health Center, Nov. 2011 to March 2012.

\begin{tabular}{llll}
\hline Antimicrobial agents & $\begin{array}{l}\text { Susceptible } \\
\text { No. (\%) }\end{array}$ & $\begin{array}{l}\text { Intermediate } \\
\text { No. (\%) }\end{array}$ & $\begin{array}{l}\text { Resistance } \\
\text { No. (\%) }\end{array}$ \\
\hline Ampicillin & $0(0)$ & $2(11.1)$ & $16(88.9)$ \\
Cotrimoxazole & $7(38.9)$ & $1(5.6)$ & $10(55.6)$ \\
Chloramphenicol & $8(44.4)$ & $0(0.0)$ & $10(55.6)$ \\
Norfloxacin & $18(100)$ & $0(0.0)$ & $0(0.0)$ \\
Tetracycline & $4(22.2)$ & $0(0.0)$ & $14(77.8)$ \\
Gentamicin & $12(66.7)$ & $1(5.5)$ & $5(27.8)$ \\
Ceftriaxone & $17(94.4)$ & $1(5.6)$ & $0(0.0)$ \\
Nalidixic acid & $10(55.5)$ & $3(16.7)$ & $5(27.8)$ \\
Ciprofloxacin & $18(100)$ & $0(0.0)$ & $0(0.0)$ \\
\hline
\end{tabular}

DOI: http://dx.doi.org/10.4314/ejhs.v28i2.11 


\section{DISCUSSION}

The overall prevalence of Salmonella species in this study was $7.3 \%$. This is in agreement with a study conducted in Yemen, 6.8\% (11), and higher than the findings reported in Addis Ababa, 3.8\% (12). But was lower than the $15.4 \%$ isolation rate reported from Jimma (13).

The variability of isolation of Salmonella may be attributable to the difference in study areas and period because the features of the disease vary from place to place and time to time depending on the local meteorology, geography and socioeconomic elements (13).

According to this study, the isolation rate of Salmonellosis was higher in children of less than 5 years old, which is in accordance with previous study done in Iran (14). This might be due to age difference, because children are less likely to wash their hands after defecating than adults, more likely to put their fingers or dirty objects into their mouth and also more likely to play in soil where they may come into contact with faeces.

In this study, the majority of Salmonella isolates were resistant to ampicillin (89.5\%), Tetracycline (89.5\%), chloramphenicol (78.9\%) and co-trimoxazole (57.9\%). This observation is in contrast with findings from Brazil (19) where most of the isolates were sensitive to ampicillin (40.7\%), chloramphenicol (64.4\%), tetracycline $(40.7 \%)$ and co-trimoxazole $(59.3 \%)$.

Compared to a previous report from Jimma (13), greater than fourfold increase in resistance to gentamicin from $1.7 \%$ to $15.8 \%$ was observed in the present study. This increase might be because of the relatively increased irrational use of the antibiotics in Meklle. In developing countries like Ethiopia, antibiotics are carelessly used by patients and physicians. It is thus a common practice that antibiotics can be purchased without prescription, which leads to misuse of antibiotics by the public contributing to the emergence and spread of antimicrobial resistance $(8,15)$.

Resistance to two or more drugs was observed in $100 \%$ of the isolates in this study. The organisms seem to have increased their resistance to the drugs from lower levels reported earlier (20) to levels of more than $90 \%$ in reports by Asrat (8). This is similar to the pattern across the globe where the organisms have consistently increasing their resistance to these commonly used first line drugs. This is a sharp increase from earlier reports indicating the aggravating problem of drug resistance by these microbes over the years. Multidrug resistant Salmonella isolates have become an issue of worldwide concern (14).

The isolation of Shigella species (6.9\%) in this study is in agreement with those reports from Harar 6.9\% (20), Gondar 7.5\% (17) and Brazil $7.1 \%$ (19), but lower than findings in Addis Ababa $11.7 \%$ (12) and Jimma 20.1\% (16) from similar study participants.

Higher isolation rate $(66.7 \%)$ of the Shigella isolates was found in children of less than 5 years of old. This might indicate that Shigellosis was the problem of children of under 5 years of age in Mekelle, which is in agreement with studies conducted in Gondar (17).

Mucus in the stool, with or without blood, was the main characteristic of Shigella infection, found in 50\% (9/18) of patients, although shigellosis was statistically associated only in patients with bloody diarrhoea, which is in agreement with reports from Harar, Ethiopia (20).

However, in contrast with a study conducted in Addis Ababa, where the majority (82.4\%) of the diarrhoeal samples in which Salmonella and Shigella were isolated, had watery nature (8). This may reflect the underlying geographic variations in strain patterns from place to place. In developing countries, Sh. dysenteriae and Sh. flexneri are prevalent species causing mucoid to bloody diarrhoea, while in developed countries, Sh. sonnei and $S h$. boydi species predominate. Shigellosis is commonly associated with mild watery diarrhoea. While Sh. dysentriae are consistently associated with dysentery, it is less common for Sh. flexneri to cause bloody diarrhoea (1).

Among all antibiotics tested for Shigella species, the highest resistance was observed with ampicillin $(88.9 \%)$, tetracycline $(77.8 \%)$, chloramphenicol $(55.6 \%)$ and cotrimoxazole $(55.6 \%)$. These findings are in agreement with the previous studies conducted in different places and

DOI: http://dx.doi.org/10.4314/ejhs.v28i2.11 
times in Ethiopia $(8,17,18)$. Compared to previous studies reported in Ethiopia $(8,16,17,18)$, Shigella isolates had a higher level of resistance to gentamicin $(27.8 \%)$. This may be due to the indiscriminate overuse of the drug in the community.

In agreement to studies conducted in Jimma, Gondar and Addis Ababa $(8,16,17,18)$ Shigella isolates were highly resistant to ampicillin. However, there seems to be a lower pattern of resistance to the drug in studies reported from Brazil (19). This could be due to the fact that ampicillin has been used in Brazil for a long time and because of its easy availability and potential for misuse. The antimicrobial resistance patterns of Shigella species vary according to geographic region and in the same place over time, leading to a therapeutic problem. Such differences are never stable and may change rapidly especially in places where antibiotics are used excessively, particularly in developing countries.

Of the Shigella isolates, 17(94.4\%) were found to be resistant to one or more antimicrobial agent(s), and $16(88.9 \%)$ were multi-drug resistant, which is comparable with findings from Gondar, where $90.8 \%$ and $87.8 \%$ of the isolates were resistant to one or more antimicrobial agent(s) and multi-drug resistant respectively (18).

Several factors may contribute to resistance by pathogens causing gastroenteritis in developing countries like Ethiopia. These include frequent overuse, misuse and factors related to the potency and quality of antimicrobials and the distribution of resistant strains (8). In addition, syndromic diagnosis and diagnostic imprecision usually force physicians to adopt for broad spectrum antibiotics such as amoxicillin and tetracycline, over prescribing and less antibiotic diversity which lead to the emergence and spread of antimicrobial resistance. Fortunately, there seems to be limited resistance to ciprofloxacin norfloxacine and ceftriaxon. However, given the current trends in Ethiopia, unless intensive efforts are made to stem the unrestricted use of antimicrobials in Mekelle, it will not probably be long before the microbes develop resistance to these expensive drugs and complicate effective treatment of gastroenteritis (15).
It was not possible to conduct Shigella and Salmonella serogrouping/serotyping due to lack of antisera. This study gives a brief overview of the burden and distribution of Shigella, Salmonella and intestinal parasite related diarrhoeal disease in children. The overall prevalences of Salmonellosis, Shigellosis and intestinal parasitosis were $7.3 \%$, $6.9 \%$ and $31.9 \%$ respectively with greater than $2 / 3$ of the Salmonellosis and Shigellosis cases found in children of less than 5 years old. Accordingly, Shigella and Salmonella were still challenging in children especially of less than 5 years old. High antibiotic resistance was observed among both isolates particularly to ampicillin, tetracycline, chloramphenicol and cotrimoxazole. Resistance to two or more antibiotics was observed in $100 \%$ and $88.9 \%$ of Salmonella and Shigella species respectively. Only ciprofloxacin, norfloxacin and ceftriaxone were effective for both isolates. These findings reinforce the need for continous surveillance program and strengthened infection control system to reduce the rate of infection and to apply appropriate guidelines for the use of therapeutic antibiotics.

\section{ACKNOWLEDGEMENTS}

This work was supported financially by Addis Ababa University. Laboratory reagents and a control strain was supported by Ethiopian Health and Nutrition Research Institute.

\section{REFERENCES}

1. Cheesbrough M. District Laboratory Practice in Tropical Countries. Cambridge university press, 2nd ed. part 2006;2:97105.

2. WHO. Why children are still dying and what can be done. WHO Bulletin, 2009.

3. 3. Alper J. Data Gaps Need Bridging To Assess Infectious Gastrointestinal Diseases. ASM News, 2003; 69: 65-68.

4. FMOH . National Strategy For Child Survival In Ethiopia. Family Health department, Addis Ababa, Ethiopia, 2005.

5. Vargas M, Njg, Casals C, Schellenberg D, Urassa H, Kahigwa E, Ruiz J, Vila J. Etiology

DOI: http://dx.doi.org/10.4314/ejhs.v28i2.11 
of Diarrhea In Children Less than Five Years of Age In Ifakara, Tanzaia. Am J Trop Med Hyg 2004;70: 536-539.

6. Kansakar P, Baral P, Malla S, Ghimire GR. Antimicrobial susceptibilities of enteric bacterial pathogens isolated in Kathmandu, Nepal, during 2002-2004. J Infect Dev Ctries, 2011;5: 163-168.

7. Isenbarger DW, Hoge CW, Srijan A, Pitarangsi C, Vithayasai N, Bodhidatta L, Hickey KW, Cam PD. Comparative antibiotic resistance of diarrheal pathogens from Vietnam and Thailand, 1996-1999. Emerg Infect Dis, 2002;8: 175-180.

8. Asrat D. Shigella and Salmonella serogroups and their antibiotic susceptibility patterns in Ethiopia. East Mediterr Health J, 2008 14: 760-767.

9. TRHB. Tigray Health Bureau Profile of 2010. Tigray health bureau, Mekelle, 2010.

10. CLSI. Performance standards for antimicrobial susceptibility testing. M100S16, Sixteenth informational supplement. Clinical and Laboratory Standards Institute document M2-A9, 2006.

11. Banajeh SM, Ba-oum NHS, Al-sanabani RMN. Bacterial aetiology and anti-microbial resistance of childhood diarrhoea in Yemen. $J$ Trop pediatr, 2001; 47:301-303.

12. Asrat D, Hathaway A, Ekwall E. Studies on enteric campylobacteriosis in Tikur Anbessa and Ethio-Swedish children's hospital, Addis Ababa, Ethiopia. Ethiop Med J, 1999;37: 7184.

13. Mache A. Salmonella Serogroups and their Antibiotic Resistance Patterns Isolated From Diarrhoeal Stools of Pediatric Out-Patients in Jimma Hospital and Jimma Health Center,
South West Ethiopia. Ethiop. J. Health sci 2002;12: 37-46.

14. Prakash K. Epidemiology and Antimicrobial Resistance of Enteric Pathogens in Dhahira Region, Oman. Iran J Publ Health, 2008;37: 60-69.

15. Okeke IN, Ojo O, Lamikanra A, Kaper JB. Etiology of Acute Diarrhea in Adults in Southwestern Nigeria. $J$ Clin Microbiol, 2003;41: 4525-4530.

16. Mache A. Antibiotic resistance and serogroup of shigella among pediatric out-patients in Southwest Ethiopia. East Afric Med J, 2001;78: 296-299.

17. Tiruneh M. Serodiversity and anti-microbial resistance pattern of Shigella isolates at Gondar University Teaching Hospital,Northwest Ethiopia. Jpn J Infect Dis, 2009; 62: 93-97.

18. Yismaw G, Negeri C, Kassu A. A five-year antimicrobial resistance pattern observed in Shigella species isolated from stool samples in Gondar University Hospital, northwest Ethiopia. Ethiop J Health Dev, 2006; 20: 194198.

19. Diniz-Santos DR, Silva Lrsan (2006). Antibiotics for the Empirical Treatment of Acute Infectious Diarrhea in Children. BJID 10: 217-227.

20. Reda AA, Seyoum B, Yimam J, Andualem G, Fiseha S, Vandeweerd JM. Antibiotic susceptibility patterns of Salmonella and Shigella isolates in Harar, Eastern Ethiopia. $J$ Infect Dis Immun; 2011; 3: 134-139. 